\title{
THE GESTATION OF CROSS-CULTURAL MUSIC RESEARCH AND THE BIRTH OF ETHNOMUSICOLOGY
}

\author{
P. G. TONER
}

\section{INTRODUCTION}

This article examines the development of cross-cultural music research, from its earliest days in the collection, notation and analysis of "primitive music" and "folk songs" to the first annual meeting of the Society for Ethnomusicology in 1956. The gestation period was long, and the birth, like all births, was largely unheralded and was most significant to the immediate family. Now that ethnomusicology is entering middle age, its true significance can perhaps be better appreciated.

The history of cross-cultural music research parallels the history of cross-cultural research more generally, with some interesting and significant differences. As in anthropology, the evolutionist perspective of early ethnomusicology gave way to functionalism and then to more interpretive approaches, but it has been suggested that the discipline has dragged its feet theoretically and theoretical change has been slow. ${ }^{1}$ Ethnomusicology has been influenced throughout its history by its two parent disciplines, anthropology and musicology, ${ }^{2}$ a process that has at times been harmonious and, at other times, like a custody battle. And, more than many other disciplines, the development of ethnomusicology has been closely tied to technological changes such as the invention of the phonograph. There are, then, unique and distinctive lessons to be learned by historicizing cross-cultural music research. In this article, I will attempt to take stock of these lessons, and to consider the impact this field of research has had on cross-cultural research more broadly. I will also consider in some detail how the development of ethnomusicology has influenced Australian Aboriginal ethnography, specifically in northeast Arnhem Land, and the early development of Australian Aboriginal studies.

This article will also consider the place of two pioneering ethnomusicologists who were concerned with the study of Australian Aboriginal music, and whose research represents the end-point of the trajectory to be described below. The American ethnomusicologist Richard Waterman was not the first to make field recordings of Aboriginal music in Arnhem Land, nor was he the first to analyze recordings of Aboriginal music. He was, however, the first ethnomusicologist to conduct long-term, primary research in the region, and to make a substantial number of field recordings. Waterman was a student of Melville Herskovits, who was himself a student of 
Franz Boas, and so Waterman is firmly placed within the anthropological branch of ethnomusicology. The Australian ethnomusicologist Alice Moyle probably did more in her distinguished career for the discipline's development in Australia than any other scholar. She was a prolific recordist, although her periods in the field were relatively brief. Moyle began her studies of Aboriginal music under Donald Peart, the first professor of music at the University of Sydney, and her research reveals a firm grounding in the musicological branch of ethnomusicology.

These two scholars began their research on Australian Aboriginal music in the early- to-mid 1950s, roughly coinciding with the formation in the U.S. of the Society for Ethnomusicology. In late 1952 the music scholars David McAllester, Alan Merriam, Willard Rhodes and Charles Seeger met to discuss how to facilitate communication between scholars with common interests; in 1953 they sent out a letter to 66 people to solicit interest, which 10 people signed (including Waterman). The first Ethno-Musicology Newsletter appeared later that year. The first annual meeting of the Society occurred in September 1956. ${ }^{3}$ For the purposes of this article, I take the foundation of this society as formally marking the birth of the discipline known as "ethnomusicology", even though the academic study of non-Western musics is much older. ${ }^{4}$

So what do we have? We have the formation of a scholarly society from a number of diverse origins, whose membership is roughly split between anthropologists and musicologists with a common interest in non-Western and/or folk musics. And we have two scholars of Australi- an music who began their research on that topic during the same formative period, each representing fairly clearly one of the two orientations which are still with us today - although I will demonstrate that their complex research paths cannot be characterized in a simplistic way. In this article I want to examine the intellectual trajectory that led to that formative period, to examine an unusual and lengthy period of gestation which led to this peculiar and hybrid birth.

\section{EXPLORERS AND PHILOSOPHERS}

Attention to music in situations of crosscultural contact occurred very early in the record of European exploration. The Calvinist missionary Jean de Léry visited Brazil for 10 months in 1557-58, and his book History of a journey made into the land of Brazil, otherwise called America, first published in 1578, includes numerous descriptions of musical performance, as well as music notations in the third edition of $1585^{5}$ - surely among the first studies of non-Western music. Léry describes native Brazilian instruments, dancing that accompanied musical performances, and the singing style of the "savages", 6 and his account was incorporated into Montaigne's 1580 essay "Des cannibales". 7

Another early work to consider nonWestern music was Charles de Rochefort's The history of the Caribby-Islands. Translated in 1666 by the Englishman John Davies of Kidwelly, de Rochefort's book includes a number of passages relating to the music of the Caribbean, including the following: 
To divert themselves they also make several Musical Instruments, if they may be so called, on which they make a kind of harmony: Among others they have certain Tabours or Drums made of hollow Trees, over which they put a skin only at one end... To this may be added a kind of Organ which they make of Gourds, upon which they place a cord made of the string of a reed which they call Pite; and this chord being touch'd makes a sound which they think delightful. The concerts of divers other Savages are no better than theirs, and no less immusical to their ears who understand Musick. In the morning, as soon as they are up, they commonly play on the Flute or Pipe; of which Instrument they have several sorts, as well polish'd and as handsom as ours, and some of those made of the bones of their Enemies: And many among them can play with as much grace as can well be imagin'd for Savages. ${ }^{8}$

John Barrow's 1806 tome An account of travels into the interior of Southern Africa in 1797 and 1798 includes the following passage:

It has frequently been observed that a savage who dances and sings must be happy. With him these operations can only be the effects of pleasurable sensations floating in his mind: in a civilized state, they are arts acquired by study, followed by fashion, and practised at appointed times, without having any reference to the passions. If dancing and singing were the tests by which the happiness of a Hottentot was to be tried, he would be found among the most miserable of all human beings. ${ }^{9}$

Although amusing when examined retrospectively, passing references to music do not make an important contribution to the development of ethnomusicology as a field of study, any more than old maps with "there be monsters here" attributed to unknown regions made an important contribution to the development of geography. These passages merely give us a taste of the European mindset which was present as the colonizing powers expanded their grasp around the world.

One early thinker, however, does stand out as having delineated at a very early stage some of the key orientations that would come to define the field of ethnomusicology, and that was Rousseau in his A Complete Dictionary of Music of 1779. The ethnomusicologist Anthony Seeger has interpreted Rousseau's work as addressing some of the same questions that have occupied those working in the field ever since. One of these issues is that the transcription of musical sounds is a means to understand the physical laws of music; as Seeger writes, "musical transcriptions reveal certain similar sound processes governed by laws of acoustics", 10 and he points out that careful transcription has been a characteristic feature of most ethnomusicological studies. Rousseau's study itself included transcriptions of Chinese, Persian, Native Canadian and Swiss songs. ${ }^{11}$

A second pervasive ethnomusicological issue identified by Seeger in Rousseau's work is his emphasis on the cultural interpretation of music, exemplified by a cer- 
tain Swiss air which provoked such a strong reaction among Swiss troops that it was banned, although Rousseau states that the transcription itself reveals no musical structures which could be responsible. $^{12}$

In other words, Rousseau identified in his eighteenth-century writing the two dominant orientations of ethnomusicology, a discipline that did not begin to take form for another century: the first geared around careful transcription and musical analysis as the basis for understanding the music of the Other; and the second geared around an interpretation of music based on its cultural context. These sometimesopposed, but never entirely exclusive, approaches have been a feature of ethnomusicology down to the present day, and are well exemplified by the work of Waterman and Moyle, of which more later.

\section{COMPARATIVE MUSICOLOGY}

Ethnomusicology, as it is now known, was first manifested as an organized academic field of study under the rubric "comparative musicology" in the late-nineteenth century. A common view is that one of its founders was the tone-deaf ${ }^{13}$ British physicist A. J. Ellis, whose best-known work was his 1885 article "On the musical scales of various nations". As a physicist and musical enthusiast, Ellis' interest was in using the methods of acoustics to measure the characteristic pitches and intervals of musical scales of different musical cultures with the aim of comparing them. Ellis' starting point, however, was his understanding (as a physicist) that the interval between any two notes: ...is measured properly by the ratio of the smaller pitch number to the larger, or by the fraction formed by dividing the larger by the smaller. When these ratios are known for each successive pair of notes, the scale itself is known, for means then exist for tuning the whole scale when one of its notes is given. ${ }^{14}$

As Jaap Kunst explains in a discussion of Ellis' paper, an octave is represented by a 2:1 ratio, a perfect fifth by a 3:2 ratio, and a perfect fourth by a $4: 3$ ratio. When the two pitches have no lowest common denominator, the ratios become very unwieldy and a logarithmic table is used. ${ }^{15}$

His long paper was originally a talk given to the Society of Arts with many accompanying illustrations on various instruments, including a dichord, a number of English concertinas specially tuned to different scales, a sitar, a koto and a set of Chinese bells. The research on which the talk was based was done with instruments obtained privately or through museum collections, some of which had fixed tuning (and therefore which could be investigated independently), and others which had to be played by native musicians; these included the Arabic oud, the Scots highland bagpipe, the Indian sitar and vina, Chinese flutes, mouth organs, gongs and stringed instruments, the Japanese koto, and both slendro and pelog gamelan orchestras. His treatise is full of tables and charts showing the exact frequency measurements and intervals of all of these instruments, as well as scales derived from them. Ellis reveals an ethnomusicological sensibility that is somewhat ahead of his time when he writes that it is necessary to 
be a native musician is to hear the real pitch of a musical scale, that there might be considerable variation of such a scale from musician to musician, and that, at any rate, there is a significant difference between knowing the notes used in a piece of music and the musical theory which underpins it. ${ }^{16}$

In Ellis' conclusions, he compares the principal intervals used in these different scales from all over the world, proposing how particular intervals were altered to produce distinctive scales, and even suggesting how particular musical features from one region of the world influenced another. For his final conclusion, however, Ellis writes: "the Musical Scale is not one, not 'natural,' nor even founded necessarily on the laws of the constitution of musical sound, so beautifully worked out by Helmholtz, but very diverse, very artificial, and very capricious." 17

So, even though Ellis' starting point and methodology were based on the Western conception of the physics of sound, there is also an explicit recognition that the musical practices of different cultures might be based on quite different principles. Most importantly, it has been observed that his work provided the empirical foundations for comparative musicology. ${ }^{18}$

Perhaps the most important aspect of Ellis' work was his development of a system of "cents" for the study of intervals between pitches. To measure nontempered intervals in terms of ratios of the two pitches in question is cumbersome in the extreme, and to use a logarithmic scale is only somewhat less so. Ellis' most enduring contribution to ethnomusicology was to propose the division of each semitone in the equal-tempered scale into one hundred equal increments which he called "cents"; although a difference of one cent is impossible to discriminate, Ellis felt that most sensitive ears could register a difference of five cents. ${ }^{19}$ By freeing comparative musicology from the need to negotiate complex logarithms, Ellis provided a methodological tool that not only facilitated the comparison of different tonal systems, but also maintained a strong orientation around tonality as a primary concern of the discipline.

A prominent influence on early scholars of non-Western music like Ellis was psychological theory - the idea that the study of various aspects of music, like rhythm or tonality, could reveal principles of the functioning of the human mind. Indeed, comparative musicology and psychology were very closely integrated in the late-nineteenth and early-twentieth centuries, $^{20}$ and many early research problems were oriented around the investigation of the origins and development of music and universal musical principles. ${ }^{21}$ Carl Stumpf's Tonpsychologie (1883 and 1890) was particularly influential, developing a theory of tone sensation based on individual cognition: for instance, examining the perception of similarity and difference in tonal stimuli, which led to a major focus on tonal distance and scale formation advanced by Ellis and many others. ${ }^{22}$

As Dieter Christensen has pointed out, Stumpf "believed in the unity of the human mind", 23 and required musical data from all cultures to substantiate his theories. Toward this end, and under his direction, a large collection of phonograph recordings - which eventually became the famous Berlin Phonogramm-Archiv - 
were amassed that would be analyzed for the purpose of psychological research. ${ }^{24}$ The Phonogramm-Archiv also became the basis for the development of a unique form of evolutionary theory focusing on music and, in particular, on pitch and intervallic organization. $^{25}$ As Eric Ames notes, Stumpf and his colleagues used recordings of non-Western music to emphasize musical evolution. However, evolutionary thought at the turn of the twentieth century took a variety of forms beyond a strict linear model, and Stumpf was able to construct an evolutionary discourse that accommodated notions of both development and geographical diffusion. ${ }^{26}$

Stumpf's colleagues, notably Erich von Hornbostel and Otto Abraham, continued to investigate psychological aspects of music, based primarily upon the examination of tonal systems, scales, intervals, and the like. Regardless of their commitment to the intricacies of psychological theory, other comparative musicologists certainly maintained a dominant interest in scales and melodies well into the twentieth century. As Stephen Blum notes, for many comparative musicologists "'musical system' was in effect synonymous with 'tone system'". ${ }^{27}$ Blum quotes Robert Lach as an example:

How does a scale originate? How did the human spirit - in various lands, various times, among various peoples and races - succeed in constructing its musical system, i.e., the sequence of individual scale degrees, according to various specific schemata, or "systems of tonal crystallization", so to speak, which differ so fundamentally from one another - as is evident from the various scales and tone systems? ${ }^{28}$

This emphasis on scales, melody, pitch, heterophony and polyphony - all aspects of music associated with pitch or tone was prominent in much comparative musicology, particularly in the work of Hornbostel.

A well-known example is his theory of the cycle of blown fifths, discussed in detail by Jaap Kunst. Hornbostel's theory has it that an ancient Chinese tone-sequence or scale was developed as follows: a tone of $366 \mathrm{~Hz}$ (the so-called huang chong, or "yellow bell") was produced on a length of stopped bamboo $230 \mathrm{~mm}$ in length and $8.12 \mathrm{~mm}$ in diameter. When this tube is overblown, it produces a tone a twelfth above the fundamental, which is then transposed down an octave to give the second tone of the sequence, a fifth above the fundamental; an overblown twelfth above this second tone, transposed an octave down, produces the third tone, a fifth above the second tone; and so on. A cycle produced in this way using pure fifths $(702 \mathrm{~Hz}$, a "Pythagorean" interval based on string-measurement) would arrive back at the same note from which it started after 12 jumps. However, Hornbostel noted, since the blown fifth is roughly one-tenth of a tone flat, the cycle is not completed until 23 jumps. Hornbostel postulated that before the Chinese began to construct scales based on Pythagorean principles, they must have developed their scale based on this cycle of blown fifths. Hornbostel and others discovered scales from around the world which could be derived from this principle. ${ }^{29}$ Hornbostel's complex theory has been criticized since its inception, but it 
reveals two key concerns of the comparative musicology of his day: first, a concern with the origins of musical features; and second, a belief that such origins may be revealed through the study of tones, scales and intervals.

Another example is Hornbostel's ideas about the concept of pure melody. Unlike European music, which since roughly 1600 has been based on harmony, all other music is based on pure melody. Hornbostel believed that harmony was superimposed on "natural" traits rooted in the "psychophysical constitution of man": a natural melodic movement downward ("like breathing or striking, from tension to rest"); small melodic steps of at most a major third; a "melodic unity" with a disregard for fixed scale steps; and a concern with the "distance" between notes - "the size of steps" — rather than their consonance. $^{30}$

As with Stumpf, there is an undercurrent of evolutionism in Hornbostel's speculation on melody. ${ }^{31}$ He states that short, repetitive melodies of a few notes less than a fourth apart are indicative of "an early stage of development" and are due to "a narrow range of consciousness", 32 and that the natural evolution of melody is from this level to a larger number of notes, a greater range, and longer phrasing. ${ }^{33}$ Furthermore, in his study of African music, Hornbostel believed that polyphony was a natural development from antiphony (the alternation of solo and chorus singing), probably by accident when the two parts unintentionally overlapped. However, he is clear that this polyphony is the result of a melodic, rather than harmonic, principle. ${ }^{34}$
Hornbostel's theoretical orientation is well-revealed in a 1933 article called "The Ethnology of African Sound-Instruments". Hornbostel was an advocate of a form of evolutionism, but one which was combined with the geographical diffusion of cultural traits. ${ }^{35}$ In fact, at certain points he seems to deny the validity of evolutionary theory for the purpose of understanding cultural phenomena. Of the idea that we might reconstruct the history of cultural phenomena, such as musical instruments, by arranging them according to differential features which would reveal their relative ages, Hornbostel writes: "Plausible as this reasoning sounds, its utility as a guide to method is doubtful, and theories of evolution, however ingenious, can contribute little to the classification of cultural phenomena in chronological order, which has always been accepted as one of the most important problems of ethnology." 36

In support of this critique of evolutionism, Hornbostel cites two instruments familiar to the Australian ethnographic literature: "the bull-roarer and the boomerang impress us by the subtlety of their technique, yet they belong to the Australian aborigines" $^{37}$ - which certainly qualifies as a case of damning with faint praise.

And yet, a chronological or developmental approach, whether or not we call it evolutionism, is present throughout Hornbostel's work. He states explicitly that if one phenomenon belongs exclusively to a "primitive" culture and a second belongs exclusively to a "higher" culture, then the first phenomenon is chronologically earlier ${ }^{38}$ — which seems like a case of circular reasoning. Hornbostel also gives cautious approval to Tylor's concept of 
"survivals", but does not agree with the full extent of Tylor's reasoning. Hornbostel writes that Tylor felt that "inorganic and uncomprehended phenomena belong to an earlier stage of development", 39 but he is more cautious: "[I]norganic and uncomprehended phenomena are therefore merely an indication that we have to do with older cultural phenomena, but in what connexion, and to what culture they must be assigned, can only be decided on its merits in each individual case."40

On the subject of monogenesis vs. polygenesis, Hornbostel is unambiguously clear: it is highly unlikely that any specialized cultural phenomenon could develop independently in two different locations: ${ }^{41}$ "[T]here has never, so far as I know, been an historically verified instance of polygenesis in different cultures."42 Instead, Hornbostel advocates what he calls "the despised 'diffusion theory'", 43 arguing that some cultural phenomena may survive for a long time and may travel great distances. Any specialized cultural phenomenon, according to Hornbostel, must only have developed in one place at one time - as he famously tried to demonstrate through his theory of the "cycle of fifths". Subsequent distance of the phenomenon from the central point of origin indicates relative age. ${ }^{44}$

This leads us fairly directly to Kulturkreise theory, of which Hornbostel was an advocate. The idea is that cultures may be defined by a collection of individual characteristics (architectural, ritual, musical, social, etc.); complexes of characteristics shared by several cultures, called "culturecircles" (Kulturkreise), must have a common origin. These culture-circles have moved outwards from their points of ori- gin, have mixed, overlapped and developed, resulting in the current situation of cultural diversity. 45

Another prominent figure in comparative musicology, Curt Sachs, betrayed a more obvious evolutionist stance than Hornbostel. In his The Rise of Music in the Ancient World: East and West, Sachs writes from the outset of "the plain truth that the singsong of Pygmies and Pygmoids stands infinitely closer to the beginnings of music than Beethoven's symphonies and Schubert's lieder". ${ }^{46}$ He continues by stating that "the only working hypothesis admissible is that the earliest music must be found among the most primitive peoples". 47 Later, Sachs writes that:

The songs of Patagonians, Pygmies, and Bushmen bring home the singing of our own prehistoric ancestors, and primitive tribes all over the world still use types of instruments that the digger's spade has excavated from the tombs of our Neolithic forefathers. The Orient has kept alive melodic styles that medieval Europe choked to death under the hold of harmony, and the Middle East still plays the instruments that it gave to the West a thousand years ago...The primitive and Oriental branch of musicology has become the opening section in the history of our own music. 48

Some of Sachs' writing seems almost comical in its evolutionism by today's standards, but he was by no means alone in his thinking among some scholars of his day. What is somewhat more remarkable is that this evolutionist line persisted into the 1940s, long after it had met a timely de- 
mise in mainstream anthropology. How is it that comparative musicology lagged theoretically behind cultural anthropology by at least two decades, when the two disciplines dealt with such similar subject matter?

Sachs' interpretive framework reveals not only an underlying evolutionist conceptualisation of music and its development, but also how the evolution of music is revealed through particular musical structures. As with Hornbostel, melody features prominently as one key to understanding the contemporary music of socalled "primitive" people as representing the precursors to European music. Although, "[t]o the evolutionist, one-tone melodies as a first step before the rise of two- and three-tone melodies would almost be too good to be true", 49 Sachs acknowledges that the best available information suggested that two-note melodies are the earliest that can be traced. ${ }^{50}$

Sachs refers to these basic melodies which alternate between two notes a short distance apart as logogenic, or word-born. He considers them to be "a mere vehicle for words", 51 and they evolved in an additive way; that is, certain other notes became added to the central core. ${ }^{52}$ Opposed to logogenic melodies were pathogenic melodies, which are due to "an irresistible stimulus that releases the singer's utmost possibilities"; 53 these are characterized by great force and passion at the beginning of a phrase, only to diminish and weaken toward the end. "Descending melodies", Sachs writes, "recall savage shouts of joy or rage, and may have come from such unbridled outbursts". 54 In pathogenic melodies, evolution proceeds in a divisive way; that is, the larger vocal range resulting from savage outbursts leads to the octave and larger intervals like fourths and fifths creating a skeleton for melodic development. ${ }^{55}$

Between these two extremes is melogenic music, which represents a kind of middle ground characterized by elements of both logogenic and pathogenic. At this more developed melogenic level, where melodies tend to have a range greater than a third, particular intervals tend to crystallize, "determined by simple proportions of vibration numbers": ${ }^{56}$ the $2: 1$ ratio of the octave, the $3: 2$ ratio of the fifth, and the 4:3 ratio of the fourth. Sachs' reasoning is sometimes far from convincing, as when he writes: "The strongest magnetic power emanates from the fourth - for physiological reasons it is here best to accept without attempting discretionary explanations." 57

This "magnetic attraction" results in the development of tetrachords and pentachords, and ultimately the complex melodic structures of "highly civilized peoples". 58

In a further extension of evolutionist principles, Sachs asserts that the earliest stages of music, represented by contemporary "primitive" people, also appears in the babbling songs of European toddlers. Sachs concludes: "Thus we cannot but accept their babbling as an ontogenetic reiteration of man's earliest music and, inversely, conclude that the music of today's most primitive peoples is indeed the first music that ever existed." 59

This was in 1943. It would be easier to dismiss such speculative thinking if Sachs was not so influential on others in comparative musicology - including, as will be 
discussed below, the early thought of Alice Moyle.

Ellis, Hornbostel and Sachs are only three, albeit quite influential, figures in comparative musicology, and it would be seriously misleading to suggest that their views are completely representative of an entire emerging discipline. Like any discipline, there was a great deal of internal diversity, which is suggested by the diverse backgrounds of the early practitioners: musicology, composition, physics, chemistry, phonetics. And yet, in their thought we can see some of the broad outlines which would come to characterize the "musicological" half of ethnomusicology. I have already commented on an underlying evolutionist stance, although this was not equally prominent among all scholars. Another feature was a unitary approach, viewing "the world's musics as a group of separate units, stylistically distinct and internally homogenous", 60 and therefore able to be characterized as wholes on the basis of very small samples which reflect a single set of principles. 61

The focus on melody, polyphony, scalar structures and other similar musical features has been interpreted by Bruno Nettl as reflecting some of the dominant values of Western music in the late-nineteenth century. In Germany and Central Europe, where many of the early comparative musicologists were based, standard musical training tended to stress intellectually difficult musical structures, such as melodic development and the simultaneous interaction of various parts. When the early scholars of non-Western music began their study, we see particular attention paid to these same features. ${ }^{62}$ Nettl continues:
And if normal music, to us, is polyphonic, in the broad sense, the concept of polyphony was used to show on the one hand that the non-Western music was worthy of attention because it did have, one said rather defensively, polyphony, with people performing together in incomprehensible fashion, nevertheless knowing what they were doing; but on the other hand, most of this exotic music was worthy of study precisely because it was so different, had no polyphony... The idea of a systematic polyphonic practice and of systematic music making in general - was high on the list of values among our forebears...early ethnomusicologists wanted to show that non-Western musics were systematically organized in good part because they had learned their own music with this value in mind. ${ }^{63}$

Another feature of early comparative musicology, also related to the "musicological" half of ethnomusicology, was an emphasis on the transcription of non-Western music as an end in itself. Transcribing music onto the Western staff, even after the invention of recording technology, was and still is an important aspect of ethnomusicological training and practice, ${ }^{64}$ although the necessity and accuracy of transcription has always been subject to questioning and debate. Exact notation was not even a feature of Western compositional practice until the lateeighteenth century, ${ }^{65}$ and of course the compression of an entire musical system onto five lines and four spaces representing 12 semitones per octave tends to mould 
non-Western music to our own image. Any understanding of a non-Western music which is based on a transcription in Western notation will necessarily encode our own musical values. ${ }^{66}$ Nevertheless, if we think of the transcription of music as itself an interpretive orientation, it must be one of the most pervasive in comparative musicology through its first 50 years.

So, if early comparative musicology came substantially to inform the "musicological" half of ethnomusicology, what was the intellectual trajectory that led to the sometimes-opposed, but always intertwined, "anthropological" half?

Two prominent features of comparative musicology as it developed in late-nineteenth-century Europe are an overall lack of contextualization and a universalizing comparative perspective. ${ }^{67}$ This was implicit in Ellis' large-scale comparison of scales, in Hornbostel's meticulous analysis of recordings from around the world, and certainly in Sachs' assumption of a single developmental framework for all the world's musics. These two features also proved to be a key rift within the scholarly study of non-Western music, and led to the development of a distinctive perspective within American cultural anthropology.

\section{THE ANTHROPOLOGY OF MUSIC}

What must be one of the earliest substantial references to music within anthropology appears in Franz Boas' 1888 monograph The Central Eskimo, ${ }^{68}$ which contained transcriptions and some analysis of two-dozen Eskimo songs, within the context of a comprehensive ethnography. Not only did this set the stage for an anthropological approach to the study of nonWestern music, but it represents a scholarly effort almost as early as Ellis and Stumpf in comparative musicology. Indeed, Boas and Stumpf worked together in collecting and analyzing Northwest Coast indigenous music, subsequently published by Stumpf in 1886 in Vierteljahrsschrift für Musikwissenschaft, one of the earliest journals in comparative musicology. ${ }^{69}$ So it would be a mistake to assume that comparative musicologists and anthropologists operated in isolation from one another. Nevertheless, their overall approaches to the study of non-Western music were very different in many ways. The comparative musicologists were motivated by theories about the origins and structure of music, and analyzed their materials accordingly. Boas' work on music lacked a theory of this type, ${ }^{70}$ and instead fitted into a framework of meticulous detail and ethnographic salvage work.

In addition to the music contained in The Central Eskimo, Boas published articles on Kwakiutl, Chinook, Eskimo and Sioux music between 1888 and 1925. Each of them, while focusing on music, contains the elements that have come to be associated with Boasian cultural anthropology. The article "On Certain Songs and Dances of the Kwakiutl of British Columbia"71 contextualizes several musical transcriptions of songs (presumably done by Boas himself) by including accounts of ritual, song texts, and a very lengthy version of mythology relevant to the songs. His article "Chinook Songs"72 contains three brief notations along with 38 song texts and a glossary of several dozen words. Two articles, both entitled "Eskimo Tales and Songs", 73 present song texts along 
with explanations of dozens of words used in them. His article "Teton Sioux Music"74 addresses issues of musical form, including rhythm, phrasing, and structure, and includes 11 quite detailed musical transcriptions. Although he does not approach the technical and analytical detail of the work of some comparative musicologists, Boas was on par with many, and his work on music is under-recognized, probably due to the enormous volume of work on other subjects.

Boas' impact on the cross-cultural study of music is felt most strongly not in his own research and publications, but in those of his students and their students, a legacy which has led to a number of the most significant ethnomusicologists working today. Edward Sapir, the ethnographer, linguist and poet, was also a musician and grew up in a musical family (his father was a professional cantor). ${ }^{75}$ His first in-depth work on songs was in 1910, when he transcribed over 200 Paiute (northern Arizona/southern Utah) song texts $^{76}$ and recorded 120 songs on wax cylinders. $^{77}$ Along with this material, much of it unpublished, was copious contextual information on the performances, people and places associated with the songs. ${ }^{78}$ Sapir's recordings were transcribed by his father, Jacob Sapir. ${ }^{79}$ This research led to Sapir's article "Song Recitative in Paiute Mythology", 80 which included his own musical transcriptions and musical analysis focusing primarily on rhythm. This represents a notable difference, given the strong emphasis in comparative musicology on matters of melody, scales and intervals.

Some of the fundamental differences between comparative musicological and cultural anthropological approaches to the study of non-Western music can be found in a 1912 review Sapir wrote of a publication by Carl Stumpf (Die Anfänge der Musik). Sapir offers a précis of Stumpf's belief that, in primitive music, notice was taken of "the unified effect of tones sung at consonant intervals", while other intervals "dissonant or relatively so, would in time arise by giving the voice free play within the fourth, fifth, and octave". ${ }^{81}$ Sapir criticizes this approach as being difficult to prove or disprove, and as not being based on historical data. ${ }^{82}$ As Sapir writes:

In the nature of things any such theory must be purely speculative, as the use of musical tones is far too ancient a heritage of humanity to yield its genesis to historical reconstruction. Failing historical evidence, a theory of origin can be fully convincing only when so well grounded in psychology as necessarily to exclude all other possible theories. This is hardly the case here. ${ }^{83}$

Sapir is also critical of Stumpf's over-emphasis (which could be extended much more broadly in the comparative musicology of the day) on "the purely intervalic [sic] side of music":

Music is neither purely tone nor purely rhythm. Would it not be more suggestive to think of it in terms of an association of tone production, however it might arise, with the rhythmic impulse manifested in all of man's artistic activities? Granted this impulse and the possession of vocal chords, adjustable for changes of pitch, various forms of musical expres- 
sion might be expected to arise. Several paths seem possible, the actual course or courses traversed lie beyond our ken. ${ }^{84}$

And in a similar vein, critiquing Stumpf's handling of melodic structure and musical form, Sapir writes:

I am inclined to doubt whether a purely musical study of this problem would be as fruitful as when taken in connection with songtexts, dance forms, and other features as musical execution is wont to be associated with in practice. The peculiarities of melodic forms are often due to factors that have no direct relation to musical problems as such, as witness our masses, lullabies, and bugle calls. These remarks are meant to indicate the necessity of studying the more complicated problems presented by primitive music in connection with associated cultural features. Stumpf's relative neglect throughout the book of all features that are not strictly musical in character is naturally to a large extent unavoidable, but we must not fail to realize that such one-sidedness may lead us astray in our interpretations. ${ }^{85}$

Overall, Sapir's review is quite favourable; these comments, however, indicate certain matters of interpretation and emphasis that differentiated comparative musicologists from anthropologists, matters that still, to some extent, characterize ethnomusico$\log$.

Another of Boas' students who was very influential in the development of ethnomusicology was George Herzog. Herzog is an interesting character in this narrative, as he really stands with one foot in each of the two camps that I am discussing. He first studied at the Royal Conservatory in Budapest, and was heavily influenced by the folk music research of Béla Bartók and Zoltán Kodály. ${ }^{86}$ From 1923 until 1925, Herzog worked under Hornbostel at the Berlin Phonogramm-Archiv, the most important archival institution for comparative musicology until the Second World War, and thus was part of the socalled Berlin School of Comparative Musicology. $^{87}$ In 1925 he emigrated to the United States and studied anthropology under Boas. ${ }^{88}$ Thus, in one individual we have the intellectual descendant of a variety of important approaches to the crosscultural study of music. Bruno Nettl, Herzog's most prominent student, wrote the following about Herzog's letters, which give an interesting insight into his place in the development of ethnomusicology:

Throughout the correspondence one sees the hand of Hornbostel, the comparativist and the archivebuilder, of Bartók the careful processor and analyst concerned with authenticity, of Boas the methodical fieldworker, of the confluence of folkloristics, linguistics, and ethnography...The multidisciplinary nature of American ethnomusicology is in part due to his many-sided reach. ${ }^{89}$

Another prominent student of Boas' who was greatly influential in the development of the anthropological approach to nonWestern music was Melville Herskovits, whose interest in the relationship between 
African and African-American culture was stimulated by the role of music. ${ }^{90} \mathrm{Al}-$ though Herskovits did not publish extensively on musical topics, he supervised the doctoral dissertations of both Richard Waterman and Alan Merriam (who would both be very prominent in the new field of ethnomusicology), and he made field recordings of music in Dutch Guiana, Haiti, Trinidad, Brazil, Dahomey, the Gold Coast and Nigeria. ${ }^{91}$

\section{WATERMAN AND MOYLE: CONTRASTING SCHOLARS COMPARED}

In this section, I would like to examine the particular theoretical and methodological approaches of two of the earliest scholars of Australian Aboriginal music, Richard Waterman and Alice Moyle. As well as any two ethnomusicologists, their work clearly represents the mixed parentage of the discipline, one anthropological and one musicological - although it is difficult to characterize their work in a simplistic way. Their distinctive approaches to the study of music reveal much of the discipline's past, and also the directions it came to take in the subsequent five decades.

Richard Waterman is best known as a scholar of African and African-American music, and had a distinguished anthropological pedigree through Herskovits to Boas. His doctoral research, completed in 1943, looked at African patterns in the music of Trinidad, which he pursued through a clearly anthropological framework. ${ }^{92}$ He later worked with Herskovits at Northwestern University in Chicago, becoming the founding director of the Northwestern University Laboratory of
Comparative Musicology and supervising the doctoral research of Alan Merriam, who was to become one of the leading figures in ethnomusicology. ${ }^{93}$ Merriam later wrote of Waterman's work: "overriding all else is a basic orientation toward anthropology; [Waterman] was an anthropologist first and foremost, and his ethnomusicological specialization was almost always handled within the anthropological frame of reference." 94

This orientation is most clear in Waterman's consistent theoretical interest in cultural dynamics, examining how cultural patterns, especially musical ones, are retained, reinterpreted, or fused over time. ${ }^{95}$ His best-known work in this regard examined the degree to which AfricanAmerican musics maintained African musical elements.

Waterman was most interested in rhythmic styles and their cultural context; this in itself differentiates him from a great deal of comparative musicology which had a primary focus on tonality, melody and harmony, and the analysis of music in its own terms. His 1948 paper entitled "'Hot' Rhythm in Negro Music" examined the varying tenacity of West African rhythmic patterns in a variety of African-American musics in the New World. Waterman describes "hot" as "one of those subliminal constellations of feelings, values, attitudes, and motor-behaviour patterns" 96 which manifests itself in mixed metres, percussion polyrhythms, off-beat melodic phrasing, and an overall prominence of percussion instruments. ${ }^{97}$ The degree to which these West African musical characteristics were syncretised with musics in the New World, and the particular nature of the syncretism, depended on the music- 
al styles to which they were exposed and, crucially, on the cultural context. In North America, where whites discouraged and disparaged African music and culture, African-American music is largely European in nature, with significant but submerged African features. In contrast, in Central and South America, in which there was a more accommodating cultural context, African musical elements were more evenly blended, or even dominantly West African. ${ }^{98}$ A place like Trinidad exhibits the full range of possibilities, with dominantly British and Protestant areas featuring European-derived religious and folk music with a more subtle African flavour in some areas, and music of African religious cults in others. ${ }^{99}$ From the outset, then, Waterman's work on music pertained directly to understanding the broader cultural patterns of which music was a part.

Waterman's work on African and African-American music was also critical of some of the prevailing attitudes in the academic study of non-Western music. He took issue, for instance, with the notion that Africans were not developed enough culturally to have harmony, and that any instances of harmony in recorded samples were purely the accidental result of overlapping polyphony of different vocal parts. He also lamented the methodology that facilitated such an interpretation, where analysts relied on poor-quality recordings made by others, where true harmonic features may have been masked, rather than on recordings they made themselves. ${ }^{100}$ Waterman writes: "That a hypothesis concerning the absence of harmony in African music could have been framed on the basis of early data presented, then, is completely understandable; how the hypothesis came to be accepted as fact and how it managed to persist to this day are less readily understood."101

In his work on Australian Aboriginal music, Waterman retained his overriding theoretical interest in cultural dynamics and social context, even to the extent that any focus on particular musical features is limited. He made around 15 hours of recordings of Yolngu music during a year's field research in Yirrkala in 1952/53. For the most part, they were elicited recordings of short sequences of songs, perhaps a half-dozen to a dozen, by single patrifilial groups. There are several recordings of oral narrative, and at least two sequences of songs recorded in their ritual context.

Waterman's only published work dealing specifically with Yolngu music was an article in 1955 entitled "Music in Australian Aboriginal Culture - Some Sociological and Psychological Implications". Waterman's primary focus was in examining Yolngu music as an enculturative mechanism, and he drew upon functionalist theory in his interpretations. ${ }^{102}$ Much of the article examines how music is learned in childhood, adolescence, early adulthood, and late adulthood, and the functions of music are described as providing recreation, improving morale, increasing and relieving emotional tension, ${ }^{103}$ strengthening kin-group solidarity, acting as textbooks of natural history, history and cosmology, and affirming ties between social groups and totemic species. $^{104}$

In terms of musical features, it is curious that Waterman's interest in rhythm, as detailed in his African-American research, does not replicate itself in his Yolngu research (despite considerable 
rhythmic complexity). Instead, Waterman turns his attention to subject matter closer to the heart of comparative musicology: melody, scales and intervals. Even here, though, his primary interest is to demonstrate the relationship between melody and sociality, by demonstrating the patrifilial identity of various melodic intervals. Thus, he can assert that: "[a] karma cycle of the ridajigo-speaking lineage uses the first, the flatted second, and the flatted third of scale; a cycle of the komaitt-speaking lineage uses the natural second and flatted third of scale, and one of the magkalili-speaking lineage the flatted third and the fourth."105

If the shift to a focus on melody over rhythm is somewhat surprising, the focus on social context is not. At any rate, the article as a whole does not deal with any musical feature in great detail, concentrating on matters of social function and enculturation.

Waterman's interest in cultural dynamics is more obvious in a paper, co-written with his wife, called "Directions of Culture Change in Aboriginal Arnhem Land", 106 a chapter of a book co-edited by him on the subject of cultural change in Aboriginal Australia. The paper is a critique of the view, widespread at the time, that Aboriginal culture is essentially conservative and unchanging under conditions of cultural contact, leading to cultural breakdown instead of accommodation. The Watermans advance the position that, although certain areas of Yolngu culture, such as their experience of missionary education and religion, demonstrated considerable resistance to change, in other areas of culture Yolngu people were remarkably innovative and willing to accept new things. ${ }^{107}$ In support of this position, the Watermans point to Macassan-derived material culture and cosmology, and the discovery of "new" songs in the Yolngu musical repertoire. ${ }^{108}$ The authors conclude:

...that Australian Aboriginals, as exemplified by the people of Yirkalla [sic], have earned their reputation for resisting change only in connection with changes whose motivations they do not understand, changes detrimental to their well-being, and changes that would involve behaviour in opposition to their values and to the principles of their world-view.

Actually, in their own terms, the Aboriginals of Yirkalla are people with open and questioning minds, continually making use of every source of good and valuable suggestions for the modification of their behaviour and willing to consider any innovation on its own merits. ${ }^{109}$

In his only other publication on the subject of Aboriginal music, Waterman again adopts a stance reminiscent of comparative musicology in two senses: first, through a focus on melodic structures (although he does pay attention to melodic rhythm); and second, by analyzing a collection of music made by Mountford on Groote Eylandt. In both senses, Waterman would seem to contradict the interpretive stance which he took vis-à-vis African and African-American music in the 1940s and 1950s.

Waterman's focus is to draw some tentative conclusions about Groote Eylandt music based on his melodic analyses of a 
small sample of songs. The language which he uses and the style of analysis are strongly reminiscent of early-twentiethcentury comparative musicology, and mark something of a departure from his other ethnomusicological work. There is a general interpretive assumption that the analysis of melodic structure, in the sense of counting notes and measuring the intervals between them in terms of Western musical theory, can provide material for general conclusions about the music and its place amongst the musics of the world. Thus, to give but one example, Waterman writes about one particular song in the sample:

Its basic materials are two tone levels, scored G and A. In the first measure the initial notes of the half-measure figures rise to $\mathrm{B}$, but I suspect that this is either a species of beginning formula or the singer using a few notes to find his best pitch. A peculiar feature about this song is the "rise" in measure 12 , which is echoed by a high note at the beginning of measures 13 and 14. This intrusive high note - intrusive because it is unique in this particular collection, and because it breaks the consistent pattern of alternating and balancing figurations using $G$ and $\mathrm{A}$, of which the present song is almost entirely composed reaches to a major seventh above the low note, then slides down a half-tone for its other two appearances. $^{110}$

What is surprising here is not the nature of the analysis itself, which was common enough in the mid-1960s when the paper was written, nor the value of such an analysis. What is surprising is that it comes from the pen of Waterman, whose other published work is based so strongly upon an anthropological method, copious cultural context, and a much broader approach to the analysis of musical features.

Waterman himself comments on this in the paper, noting that, although he is generally in the "anthropological" camp of ethnomusicology, one may follow the lead of Kolinski - amongst the most "musicological" of ethnomusicologists in using other people's recordings, analyzing musical structure, and ignoring the cultural context ${ }^{111}$ — an approach which he had previously characterized as "unfortunate for the development of ethnomusicology as a branch of cultural anthropo$\log y^{\prime \prime} .112$

Waterman's conclusions in this paper also situate it within a well-established discourse of comparative musicology. Given that Groote Eylandt music (at least his small sample) uses a small number of notes, he suggests that melody is better understood in terms of pitch levels rather than scales. He writes:

...this is a way of making music somewhat different from the creation of melodies using an array of notes drawn from a series that can be arranged in a scale either by the singer himself or at least by some musically trained investigator...I should like to suggest that, with regard to tonal materials, there exists a hitherto unrecognised musical culture area to go with the scale-type areas generally recognized. To the South Asian-North African microtonal area, the 
European-African diatonic area, and the Far Eastern-American Indian pentatonic area (which, incidentally, should be divided and recharacterized), I should like to add an area of Oceania characterized not by scales, but rather by the technique of forming songs out of a very few established levels of pitch. 113

Thus, here we have one of the most prominent "anthropological" ethnomusicologists, a student of Boas and Herskovits, shunning the investigation of cultural context and addressing himself to the kinds of questions which had dominated comparative musicology since the mid1880s. It is obvious that, despite being able to characterize different approaches to the study of non-Western music, some scholars cannot be completely tarred with one brush.

What, then, of Alice Moyle? In many ways, she was as good an exemplar of the "musicological" side of the discipline as Waterman was of the "anthropological" side. But, like Waterman, she cannot be entirely tarred with one brush either.

One of Alice Moyle's first publications was a book called Know Your Orchestra, ${ }^{114}$ but her first excursion into Aboriginal music was her 1957 M.A. thesis at the University of Sydney entitled "The Intervallic Structure of Australian Aboriginal Singing". The subject matter, overall approach and theoretical inspiration place her squarely within the European tradition of comparative musicology. Moyle's objective was the comparative study of intervallic resemblances among different musical traditions in Aboriginal Australia, with an eye toward describing them in terms of developmental stages. ${ }^{115}$

Moyle draws upon some of the most prominent figures in comparative musicology, especially Curt Sachs, positing a relationship between the number of notes used melodically and different stages of singing; that is, fewer notes equals an earlier stage. ${ }^{116}$ She further uses Sachs' framework of logogenic, pathogenic and melogenic singing, stating that Aboriginal song belongs in the last category due to the presence of well-marked intervals. ${ }^{117}$ Moyle also refers to Alain Danielou's "Introduction to the Study of Musical Scales", in which he states that intervals can either be divided by numbers (like string lengths), or "by their psychological correspondence such as the feelings and images they necessarily evoke in our minds", 118 extending such an idea to Aboriginal singing.

Like so much comparative musicology in the first half of the twentieth century, Moyle devotes a significant portion of her study to the subject of the pentatonic scale, and refers to both Hornbostel and Sachs in her analysis. She notes that the sequence A-G-E-D-C is a "typically Australian" mode of descent, ${ }^{119}$ and examines a number of other possible pentatonic modes. $^{120}$ She writes, however: "while the intention here is not to suggest regular or systematic pentatonism...- the reverse is nearer the truth in Australian singing - the conglomerations of small 'motives' already described do frequently produce resemblances to the above pentatonic se-

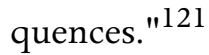

She continues: 
What remains to be said here on the subject of pentatonism is that in songs all over the continent both pentatonic, diatonic (heptatonic), chromatic, even microtonic progressions are demonstrated. And it would seem that all of these are purely vocal modes of singing which can exist side by side. Theories of "evolution" or development are probably no more than theories of emphasis, certain instruments emphasising certain scale progressions more than others. The Australian situation in this regard would closely parallel that at the beginning of Western musical history, long before subsequent experiments in harmony gave to the diatonics that "advanced" status that they had in Western musical theory. $^{122}$

It is obvious that Moyle has not been swept away by an inordinate focus on the pentatonic scale in so-called primitive music, like some of her predecessors. However, her work is clearly marked by a strong concern for scales and intervals as holding the key to understanding universal principles of musical development.

Tonality - that is, the number of tones used and the way they are used in particular intervallic sequences - is at the centre of Moyle's theory of stages of development in Aboriginal singing; ${ }^{123}$ for, as she writes, "the rise and fall of melody is surely closer to the core of music than features derived from song-texts or from dancing rhythms". ${ }^{124}$ This is combined with a corresponding theory of musical diffusion in order to speculate on the origins and spread of Australian Aboriginal music. Moyle refers to Sachs' belief that there was an Asian cradle of music which could be demonstrated by attention to melody, modes and scales. ${ }^{125}$ She writes: "Having traced — thanks to Sachs - the major-third-plus-semitone progression right to Australia's back door, we are now able to follow it further into North East Arnhem Land to the popular Wadamiri [sic] song-series which features this interval group in a well-established and striking manner." 126

And she continues:

...judging by the basic tones and intervals aboriginal singers select, it might well be that here in Australia, and for contemporary ears to hear, is music which belongs to the same deep strata as the sources of both Eastern and Western music. In Australian aboriginal music we may be hearing the same germinating cells from which have come every known style of music. $^{127}$

She then goes on to outline, based on melodic structure, a series of stages in the development of Aboriginal music, from a small range with monotonous repetition all the way through to polyphonic rudiments, ${ }^{128}$ and states that diffusion accounts for similarities between musical regions across the country. ${ }^{129}$ It seems to me that the underlying evolutionist implication of Moyle's thesis was probably imported into her thinking by her theoretical reliance on Sachs more than any other single scholar.

Moyle's primary interest in the intervallic features of Aboriginal music continued in subsequent publications. Her 1959 
analysis of Baldwin Spencer's wax cylinder recordings, made in 1901 and 1912, concentrates almost entirely on which intervals may be heard and in which order. The universal significance of particular intervals is suggested through numerous comparisons between the intervals sung on Spencer's cylinders and the ancient modes of Western civilization: "the tones of the "Arunji" corroboree...resemble those of the ancient Greek Hypophrygian, or mediaeval Mixolydian mode" 130 or "a structural interval of a fourth...is linked conjunctly to one of a fifth...after the manner of the ancient Greek Hypomixolydian and mediaeval Phrygian modes". ${ }^{131}$

In 1960, Moyle turned her analytical ear to the earliest recordings of Aboriginal music in existence, made in 1899 and 1903 of the Tasmanian singer Fanny Cochrane Smith. Once again, melodic structure provides the material for her interpretive framework, as it had in her earlier work. Comparing these songs with those of the Vedda of what was then Ceylon - the hands-down winner of the early comparative musicological prize for "most primitive" music - Moyle contends that the Tasmanian songs show a much higher level of organization, based on melodic structure, with "a compass of an octave and seven or eight appreciably different tones" and melodies which "proceed upwards as well as downwards". ${ }^{132}$ And, within the sample itself, the legato-style "Birds and Flowers" song is more musically advanced than the syllabic "corroboree" song, by virtue of melodic phrases which are "balanced above and below a tonal centre". ${ }^{133}$ In both cases, conclusions regarding musical development and sophistication are made solely on the basis of melody and melodic features, with no consideration of rhythm or timbre, much less cultural context.

Moyle's grounding in the theory of European comparative musicology also leads her to adopt an explicitly comparative approach to her material, as she details similarities and differences between the Tasmanian material and songs from the west coast of South Australia as well as Central Australia. These comparisons are based on scale tables, a method advocated by Hornbostel, which break down a piece of music into its constituent notes and their relative duration; the most frequently occurring note is taken as the tonic of a scale used in the piece. ${ }^{134}$ Moyle concludes that the Tasmanian songs have a clear tonic and an emphasis given to a triad with the tonic in the middle, whereas the other Aboriginal songs emphasize the fifth note above the triad. These and other melodic features lead Moyle to compare the Tasmanian songs with Melanesian styles of singing ${ }^{135}$ - which is obviously drawing a very long bow.

So, early in her career Alice Moyle was strongly informed by some of the characteristic features of comparative musicology: an overriding interest in melodic and intervallic structures; a negligible interest in rhythmic features; an interest in comparison, musical origins and developmental stages; a reliance on a "laboratory" method of analyzing field collections made by others; an overall lack of focus on cultural context; and a general belief in notation and musical analysis as the foundation of methodology. However, as her career progressed she became much less easy to characterize in each of these areas. A single example, an article from 1968 which was a follow-up on the Tas- 
manian recordings, reveals some subtle changes in her approach.

One notable change, which reflects an extra decade of thought on matters ethnomusicological, as well as her first-hand research and recording, is a re-orientation away from the scalar arrangement of pitches toward a focus on melodic contour, which may reveal "significant demarcations of musical style". ${ }^{136}$ To this end, Moyle's standard transcriptions in Western notation are accompanied by graphs outlining melodic contour, with pitch represented on the Y-axis and duration on the $\mathrm{X}$-axis. Of this method Moyle writes:

...the tonal level (or levels) with which the progression of vocal tones most often coincides is seen to emerge in the length and disposition of the horizontal lines. Western designations such as "tonic", "dominant" etc. are thus avoided. Vertical lines indicate "broad" (as against "narrow", or accurately measured) melodic steps or intervals...Pitch/duration graphs have the advantage here of directing attention to tonal movement, rather than to precise pitch. ${ }^{137}$

Another notable change is Moyle's much greater emphasis on the historical record to provide some relevant cultural context; in particular, in examining song texts and historical reports of polyphonic singing in parallel thirds. Although she points out that, on the Australian mainland, polyphonic singing was produced by accidental overlapping of vocal parts (the same interpretation criticized by Waterman with regard to African polyphony), she gives some credence to early historical accounts of Tasmanian singing in parallel thirds. ${ }^{138}$
However, despite these changes in her approach, and new information thereby generated, her conclusions remain virtually the same. The innovative pitch/duration graphs depicting melodic contour are used to compare Tasmanian singing not only with mainland Aboriginal singing, but also with singing in the Solomon Islands, again taking melodic features as the sole basis for intercultural musical comparison. Examining these graphs, along with the historical accounts, Moyle is able to conclude:

Compared with songs recorded on the mainland more differences than similarities have been found in the present study of Fanny Smith's songs. Fanny Smith's Spring Song and Hymn Improvisation show some structural resemblance to a style of singing hitherto observed in parts of Melanesia. And if early evidence for singing in "third parallels" be accepted, further support is thus given to a tentative theory of musical connection between Tasmania and places in the South Pacific. ${ }^{139}$

So, up to this point in her career Moyle continues to develop a speculative theory of musical diffusion, reminiscent of Hornbostel's support of diffusion theory and the monogenesis of cultural phenomena. ${ }^{140}$ Although her thought changed over the many years of her work, it can be concluded that Moyle maintained a consistent grounding in the theoretical framework of her early career, and therefore is a good representative of the "musicological" side of ethnomusicology. 


\section{CONCLUSIONS}

And so to return to my titular metaphor: the gestation of the discipline of ethnomusicology lasted for roughly seven decades, from Alexander Ellis' treatise on the musical scales of various nations in 1885 to the first annual meeting of the Society for Ethnomusicology in 1956. There was a courting period of at least 300 years, beginning with some of the earliest accounts of non-Western music by travellers and missionaries. The period of labour seems to have started between the late 1940s, with the formation of the International Folk Music Council, and late 1952, when the "founding fathers" of the Society for Ethnomusicology first met at the American Anthropological Association conference to discuss forming a new society.

Using very broad strokes (and cognizant of the dangers of doing so), it is possible to characterize some of the predominant concerns of comparative musicology as a focus on the transcription and analysis of musical structures, especially melodic, scalar and intervallic structures, as the key to an understanding of non-Western music that allows for cross-cultural comparison, generalization and speculation about the origins and development of music. Although there is considerable internal diversity, most of the main figures in comparative musicology, such as Stumpf, Hornbostel and Sachs, dealt with these issues in some detail. This intellectual trajectory provided the theoretical and methodological foundation upon which Alice Moyle built her early work on Australian Aboriginal music.
It is also possible to characterize the anthropological study of music in the latenineteenth and early-twentieth centuries as primarily concerned with the cultural context of musical performance, revealed through the process of salvage ethnography. Scholars like Boas, Sapir and Herskovits lacked any grand theory of music, although they did undertake limited transcription and analysis to complement transcriptions of song texts and detailed accounts of rituals. When they did focus on musical detail, they often singled out rhythmic structures for special consideration. This approach to the study of music paved the way for Richard Waterman's work on both African-American and Australian Aboriginal musics.

This article has many weaknesses. In order to cover much ground, I have had to gloss over each of the scholars mentioned with undue haste, very likely ignoring many of the subtleties of their work. I have left out a great many significant early scholars of non-Western musics, such as Helen Roberts, Frances Densmore, Jaap Kunst, Robert Lachmann and Hugh Tracey. I have had to ignore the entire movement of scholars who studied the folk musics of Europe, including Percy Grainger, Béla Bartók, Cecil Sharp, Marius Barbeau, Maude Karpeles and many others. Perhaps most grievously, I have left unexamined, except in a passing way, the impact of two major developments on ethnomusicology: the invention of the phonograph $^{141}$ and the development of music archives based on phonographic recordings. Both changed the course of ethnomusicology forever, and must wait for another article. 
This article has at least pointed back in time to some of the important factors which led to the intellectual situation of both the founding of ethnomusicology as a discipline and of the earliest significant research on Australian Aboriginal music. The intellectual situation then, with a smaller number of musically inclined anthropologists and a larger number of ethnically inclined musicologists, continues to characterize the discipline today. However, as the cases of Richard Waterman and Alice Moyle demonstrate, the intellectual history of ethnomusicology is quite complex and no individual scholar's development can be analyzed in a simplistic way. Waterman and Moyle each began their work on Australian Aboriginal music just as the scholarly study of non-Western music was in the process of becoming formalized as a discipline, and they were subject to a wide range of theoretical and methodological influences. Each went on to become extremely influential on the development of ethnomusicology in their respective countries as they trained future generations of researchers. As a pair, then, they shed some considerable light on the origins of ethnomusicology and the ways in which it has grown during the subsequent half-century. Now that the discipline is into late middle age, with grownup children of its own, its intellectual trajectory will no doubt continue on a robust interdisciplinary path for generations to come.

\section{ENDNOTES}

1 Timothy Rice, "Toward the Remodeling of Ethnomusicology", Ethnomusicology, vol.31 no.3, 1987, p. 471.

2 The distinction in ethnomusicology between "anthropological" and "musicological" approaches is less relevant now than it was in the past, although it still persists in a variety of ways. I maintain the distinction here only as a heuristic device for the purpose of examining the development of the discipline from these initially distinct disciplinary bases.

3 Charlotte Frisbie, "Women and the Society for Ethnomusicology: Roles and Contributions from Formation through Incorporation (1952/3-1961)" in Bruno Nettl and Philip V. Bohlman (eds), Comparative Musicology and Anthropology of Music: Essays on the History of Ethnomusicology (Chicago and London: The University of Chicago Press, 1991), pp.245-6.

4 The International Council for Traditional Music (ICTM) is the other major international society dedicated to ethnomusicological scholarship. Founded in 1947 as the International Folk Music Council (Erich Stockmann, "The International Folk Music Council/International Council for Traditional Music: Forty Years", Yearbook for Traditional Music, vol.20, 1988, p.1), the birth of this organization could also have been used in this article to mark the beginning of organized ethnomusicology. In either case, the founding of these organizations was merely a symbolic milestone marking the coalescence of a number of scholarly trends that had been developing less formally for decades.

${ }^{5}$ Frank Harrison, Time, Place and Music: An Anthology of Ethnomusicological Observation c.1550 to c.1800, (Amsterdam: Frits Knuf, 1973), p.6.

6 Ibid, pp.16-9.

7 Philip Bohlman, "Representation and Cultural Critique in the History of Ethnomusicology", in Nettl and Bohlman, Comparative Musicology and Anthropology of Music, p.131.

${ }^{8}$ Cited in Harrison, Time, Place and Music, p.56.

9 Cited in Harrison, Time, Place and Music, p.199.

10 Anthony Seeger, "Styles of Musical Ethnography" in Nettl and Bohlman, Comparative Musicology and Anthropology of Music, p.347.

11 Ibid.

12 Ibid, pp.347-8.

13 The claim of tone-deafness is made by Jaap Kunst, Musicologica: A Study of the Nature of Ethno-musicology, Its Problems, Methods and Representative Personalities (Amsterdam: Koninklijke Vereeniging Indisch Instituut, 1950), p.9. In the published paper, Ellis states: "I have been assisted throughout by the delicate ear of Mr. Alfred James Hipkins... without his remarkable power of discriminating small intervals between tones of very different qualities...this paper could not have come into existence... The calculations, the arrangement, the illustrations, as well as the original conception, form my part. The judgment of ear, musical suggestions, and assistance in every 
way form his." (Alexander Ellis, "On the Musical Scales of Various Nations", Journal of the Royal Society of the Arts, vol.33, pp.486).

14 Ellis, 'On the Musical Scales of Various Nations", pp.486-7.

15 Kunst, Musicologica, p.10.

16 Ellis, 'On the Musical Scales of Various Nations", pp.490-1.

17 Ibid, p.526.

18 Alexander L. Ringer, "One World or None? Untimely Reflections on a Timely Musicological Question" in Nettl and Bohlman, Comparative Musicology and Anthropology of Music, p.187.

19 Ellis, "On the Musical Scales of Various Nations", p.487.

20 In this sense, early ethnomusicology bears a resemblance to the early anthropology of Franz Boas, whose doctoral dissertation in physics had a definite psychological angle, examining the psycho-physics of colour perception.

21 Albrecht Schneider, "Psychological Theory and Comparative Musicology" in Nettl and Bohlman, Comparative Musicology and Anthropology of Music, p.293.

22 Schneider, "Psychological Theory and Comparative Musicology", pp.294-5.

23 Dieter Christensen, "Erich von Hornbostel, Carl Stumpf, and the Institutionalization of Comparative Musicology" in Nettl and Bohlman, Comparative Musicology and Anthropology of Music, p.204.

24 Christensen, "The Institutionalization of Comparative Musicology", p.204.

25 Eric Ames, "The Sound of Evolution", MODERNISM/modernity, vol.10 no.2, 2003, pp.303, 315 and passim.

26 Ibid, p.316.

27 Stephen Blum, "European Musical Terminology and the Music of Africa" in Nettl and Bohlman, Comparative Musicology and Anthropology of Music, p. 10 .

28 Cited in Blum, "European Musical Terminology and the Music of Africa", p.10.

29 Jaap Kunst, Around Von Hornbostel's Theory of the Cycle of Blown Fifths (Amsterdam: Koninklijke Vereeniging Indisch Instituut, 1948), pp.3-5.

30 Erich M. von Hornbostel, African Negro Music (London: International Institute of African Languages and Cultures, 1930), pp.7-8.

31 Also see Ames, "The Sound of Evolution", p.316 and passim.
32 Hornbostel, African Negro Music, p.11.

33 Ibid.

34 Ibid, p.13.

35 Ames, "The Sound of Evolution", p.316.

36 Erich M. von Hornbostel, "The Ethnology of African Sound-Instruments", Africa: Journal of the International African Institute, vol.6 no.2, 1933, p. 133.

37 Ibid.

38 Ibid, pp.138-9.

39 Ibid, p. 140.

40 Ibid, p.141.

41 Ibid, p.144.

42 Ibid, p. 145.

43 Ibid, p.146.

44 Ibid, p. 148.

45 Ibid, p.150; also see Ames, "The Sound of Evolution", ff.77.

46 Curt Sachs, The Rise of Music in the Ancient World: East and West (New York: W.W. Norton \& Co., 1943), p.20.

47 Ibid, p.21

48 Ibid, p.29.

49 Ibid, p.31.

50 Ibid, p.32.

51 Ibid, p.41.

52 Ibid, p.52.

53 Ibid, p.41.

54 Ibid, p.41

55 Ibid, p.52.

56 Ibid, p.42

57 Ibid, pp.42-3.

58 Ibid, p.43.

59 Ibid, p. 44.

60 Bruno Nettl, "Western Musical Values and the Character of Ethnomusicology", The World of Music, vol.24 no.1, 1984, p.31.

61 Ibid, p. 31.

62 Ibid.

63 Ibid, pp.32-3.

64 Ibid, p.35. 
65 cf. Lydia Goehr, The Imaginary Museum of Musical Works: An Essay in the Philosophy of Music (Oxford: Clarendon Press, 1992).

66 Nettl, "Western Musical Values", p.36.

67 Norma McLeod, "Ethnomusicological Research and Anthropology", Annual Review of Anthropology, vol.3, 1974, p.102.

68 Franz Boas, The Central Eskimo (Lincoln: University of Nebraska Press, 1964 (1888)).

69 Franz Boas, "On Certain Songs and Dances of the Kwakiutl of British Columbia", Journal of American Folklore, vol.1 no.1, 1888, p.52.

70 McLeod, "Ethnomusicological Research and Anthropology", p.102.

71 Franz Boas, "On Certain Songs and Dances of the Kwakiutl of British Columbia", p.52.

72 Franz Boas, "Chinook Songs", Journal of American Folklore, vol.1 no.3, 1888.

73 Franz Boas, "Eskimo Tales and Songs", Journal of American Folklore, vol.7 no.24, 1894, and "Eskimo Tales and Songs", Journal of American Folklore, vol.10 no.37, 1897.

74 Franz Boas, "Teton Sioux Music", Journal of American Folklore, vol.38 no.148, 1925.

75 Robert Franklin and Pamela Bunte, "Edward Sapir's Unpublished Southern Paiute Song Texts", in Regna Darnell and Judith Irvine (eds), Collected Works of Edward Sapir, vol.4: Ethnology, (Berlin: Mouton, 1994), p.589.

76 Franklin and Bunte, "Edward Sapir's Unpublished Southern Paiute Song Texts", p.589.

77 Thomas Vennum, "The Tony Tillohash Wax Cylinder Recordings and Jacob Sapir's Musical Transcriptions", in Darnell and Irvine, Collected Works of Edward Sapir, vol.4, p.663.

78 Franklin and Bunte, "Edward Sapir's Unpublished Southern Paiute Song Texts", p.594.

79 Ibid, p. 589.

80 Edward Sapir, "Song Recitative in Paiute Mythology", Journal of American Folklore, vol.23 no.90, 1910.

81 Edward Sapir, "Review of Carl Stumpf, Die Anfdnge der Musik", in Darnell and Irvine, Collected Works of Edward Sapir, vol.4, p.141.

82 Ibid, p.141.

83 Ibid, pp.141-2.

84 Ibid, p. 142.

85 Ibid, pp.143-4.
86 Bruno Nettl, "The IFCM/ICTM and the Development of Ethnomusicology in the United States", Yearbook for Traditional Music, vol.20, p.21.

87 Christensen, "The Institutionalization of Comparative Musicology", p.206.

88 Nettl, "The IFCM/ICTM and the Development of Ethnomusicology in the United States", p.21.

89 Bruno Nettl, "The Dual Nature of Ethnomusicology in North America: The Contributions of Charles Seeger and George Herzog", in Nettl and Bohlman, Comparative Musicology and Anthropology of Music, pp.271-2.

90 McLeod, "Ethnomusicological Research and Anthropology", p.102.

91 Richard A. Waterman, "“Hot" Rhythm in Negro Music", Journal of the American Musicological Society, vol.1 no.1, 1948, p.24.

92 Alan Merriam, "Richard Alan Waterman, 1914-1971", Ethnomusicology, vol.17 no.1, 1973, p.73.

93 Ibid, p.74.

94 Ibid.

95 Ibid.

96 Waterman, "'Hot' Rhythm in Negro Music", p.24.

97 Ibid, p.25.

98 Ibid, pp.26-7.

99 Ibid, pp.33-6.

100 Richard A. Waterman, "African Influence on the Music of the Americas", in Sol Tax (ed.), Acculturation in the Americas (Chicago: The University of Chicago Press, 1952), p.208.

101 Ibid, p.209.

102 Richard A. Waterman, "Music in Australian Aboriginal Culture: Some Sociological and Psychological Implications", Journal of Music Therapy, vol.5, 1955, p.41.

103 Ibid, p.45.

104 Ibid, p.47.

105 Ibid, p.46.

106 Richard A. Waterman and Patricia Panyity Waterman, "Directions of Culture Change in Aboriginal Arnhem Land", in Arnold R. Pilling and Richard A. Waterman (eds), Diprotodon to Detribalization: Studies of Change among Australian Aborigines (East Lansing: Michigan State University Press, 1970), pp.101-109.

107 Waterman and Waterman, pp.103-7.

108 Ibid, pp.107-8.

109 Ibid, pp.108-9. 
110 Richard A. Waterman, "Aboriginal Songs from Groote Eylandt, Australia", in Peter Crossley-Holland (ed.), Proceedings of the Centennial Workshop on Ethnomusicology (Victoria: Provincial Archives of British Columbia, 1975), p.105.

111 Waterman, "Aboriginal Songs from Groote Eylandt, Australia", p.111.

112 Waterman, "African Influence on the Music of the Americas", p.208.

113 Waterman, "Aboriginal Songs from Groote Eylandt, Australia", p.112.

114 Alice M. Moyle (as Alice Brown), Know Your Orchestra (Melbourne and London: F.W. Cheshire, 1948).

115 Alice M. Moyle, The Intervallic Structure of Australian Aboriginal Singing (M.A. Thesis, Department of Music, University of Sydney), 1957, p.6.

$\begin{array}{ll}116 & \text { Ibid, p.27. } \\ 117 & \text { Ibid, p.29. } \\ 118 & \text { Ibid, p.37. } \\ 119 & \text { Ibid, p.54. } \\ 120 & \text { Ibid, p.55. } \\ 121 & \text { Ibid, p.55. } \\ 122 & \text { Ibid, p.58. } \\ 123 & \text { Ibid, p.60. } \\ 124 & \text { Ibid, pp.67-8. } \\ 125 & \text { Ibid, pp.61-2. } \\ 126 & \text { Ibid, p.62. } \\ 127 & \text { Ibid, p.63. } \\ 128 & \text { Ibid, p.64. } \\ 129 & \text { Ibid, p.81. }\end{array}$

130 Alice M. Moyle, "Sir Baldwin Spencer's Recordings of Australian Aboriginal Singing", Memoirs of the National Museum, vol.24, 1959, p.20.

131 Ibid, p.21.

132 Alice M. Moyle, "Two Native Song-Styles Recorded in Tasmania", The Papers and Proceedings of the Royal Society of Tasmania, vol.94, 1960, p.73.

133 Ibid, p.73.

134 Ibid, p.74.

135 Ibid, p.75.

136 Alice M. Moyle, "Tasmanian Music, An Impasse?", Records of the Queen Victoria Museum, vol.26, 1968, p.2.

137 Ibid, p. 5.
138 Ibid, p.5.

139 Ibid, p.6.

140 von Hornbostel, "The Ethnology of African Sound-Instruments", p.146.

141 cf. Erica Brady, A Spiral Way: How the Phonograph Changed Ethnography (Jackson: University Press of Mississippi, 1999). 